\title{
Propionispora hippei sp. nov., a novel Gram-negative, spore-forming anaerobe that produces propionic acid
}

\author{
Dunja Manal Abou-Zeid, ${ }^{1}$ Hanno Biebl, ${ }^{1}$ Cathrin Spröer ${ }^{2}$ \\ and Rolf-Joachim Müller ${ }^{1}$ \\ ${ }^{1}$ GBF - Gesellschaft für Biotechnologische Forschung mbH, Mascheroder Weg 1, D-38124 \\ Braunschweig, Germany \\ ${ }^{2} \mathrm{DSMZ}$ - Deutsche Sammlung von Mikroorganismen und Zellkulturen, Mascheroder Weg $1 \mathrm{~b}$, \\ D-38124 Braunschweig, Germany
}

Correspondence

Hanno Biebl

hbi@gbf.de

\begin{abstract}
A Gram-negative, spore-forming anaerobe, $\mathrm{KS}^{\top}$, was isolated from an enrichment culture that was set up for anaerobic degradation of the aliphatic polyester poly(propylene adipate). The strain had the cellular organization of Sporomusa, vibrio-shaped cells and terminal round spores, and fermented sugars and sugar alcohols to propionic and acetic acid. Based on the morphological and physiological features as well as on a 16S rRNA gene similarity of $98 \%$, it was grouped with Propionispora vibrioides. A relatively low DNA-DNA hybridization value with the type strain of this species (47\%), and differences in substrate utilization and spore morphology, suggested that the strain should be classified in a separate species, Propionispora hippei sp. nov., with $\mathrm{KS}^{\top}$ as the type strain (=DSM $15287^{\top}=$ ATCC BAA $\left.-665^{\top}\right)$.
\end{abstract}

Recently, Biebl et al. (2000) described a novel genus and species of anaerobes, Propionispora vibrioides, which belongs to the Sporomusa-Pectinatus-Selenomonas group, as defined by Strömpl et al. (1999). The type species of Propionispora resembles Sporomusa in cell shape and spore formation (Möller et al., 1984), but its fermentation type is that of propionic-acid bacteria and is not acetogenic. In the course of a screening programme for the anaerobic degradation of natural and synthetic polyesters (Abou-Zeid et al., 2001; Abou-Zeid, 2001), a strain was isolated that proved to be morphologically and physiologically very similar to $P$. vibrioides. However, on the basis of low DNA-DNA hybridization values with $P$. vibrioides, and differences in 16S rRNA gene sequence, substrate utilization and spore morphology, we propose that the isolated strain be classified as a novel species within the genus Propionispora.

The isolate was obtained from an enrichment culture set up to examine the biological degradability of the aliphatic copolyester SP 3/6, a condensate of 1,3-propanediol and adipic acid, under anaerobic conditions. A mineral salts medium was used, and was prepared according to the anaerobic cultivation techniques recommended by Hungate

Published online ahead of print on 23 January 2004 as DOI 10.1099/ ijs.0.03054-0.

The GenBank/EMBL/DDBJ accession number for the 16S rDNA sequence of Propionispora hippei $\mathrm{KS}^{\top}$ is AJ508927.

Details of the time-course of polymer degradation by $P$. hippei are available as supplementary material in IJSEM Online.
(Abou-Zeid et al., 2001; Holdeman et al., 1977). The heatlabile polymer was prepared as a thin-film disc of $2.5 \mathrm{~cm}$ diameter (Witt et al., 1994), sterilized by UV radiation and introduced aseptically into cold, autoclaved medium under sterile nitrogen. Sewage sludge from the municipal treatment plant in Gifhorn (Lower Saxony, Germany) was used as inoculum.

For isolation, $0 \cdot 1 \mathrm{ml}$ of the culture was plated on three complex agar media (anaerobic TVLS, Brewer's anaerobic and thioglycolate medium; all from Merck). The plates were incubated anaerobically at $35^{\circ} \mathrm{C}$ in an anaerobic chamber. A first attempt after 3 months of incubation failed, but, after another 15 months, colonies developed on all three media. Fifteen colonies were checked on mineral salts agar with emulsified SP 3/6 polymer (for preparation see Witt et al., 1994); nine of them formed clear zones indicating degradation of the polymer. They were purified on complex agar medium and rechecked on polymer agar. One strain, KS, attracted attention by its curved cells and conspicuous spores and was characterized further; the others were straight rods and were not investigated further.

Cells of strain $\mathrm{KS}^{\mathrm{T}}$ were vibrio-shaped in exponentially growing cultures and formed slightly curved rods during the fermentation phase. Spores were readily formed in peptone-yeast extract-glucose, thioglycolate medium and mineral salts medium containing fructose. The sporangia were distinctly swollen, either dark or refractive, and appeared in terminal position. Vegetative cells could not be 

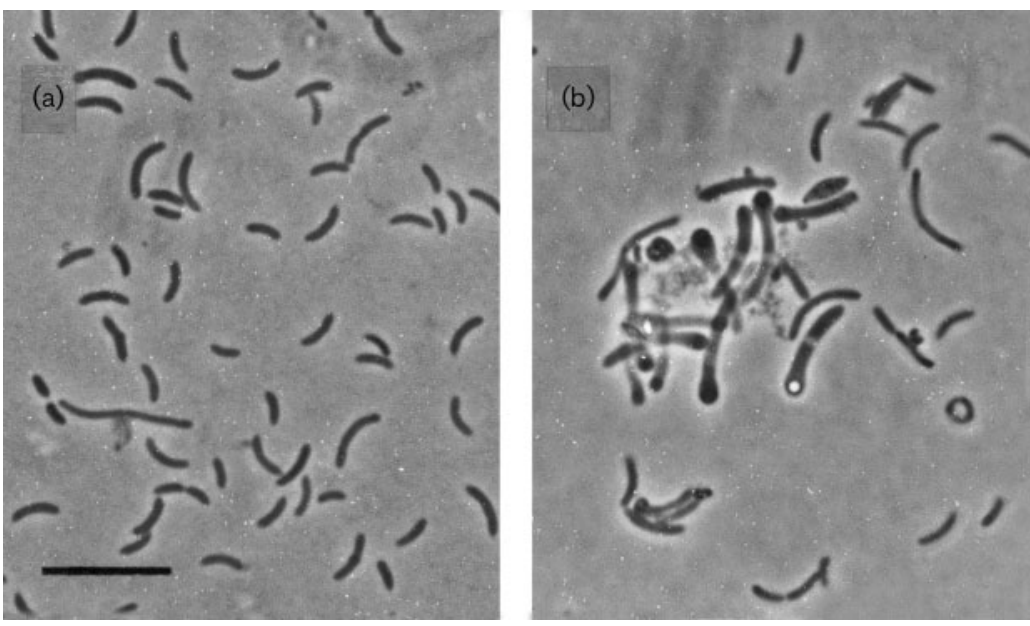

Fig. 1. Phase-contrast micrographs of strain $\mathrm{KS}^{\top}$ grown on glucose. After $24 \mathrm{~h}$ growth (a); after $48 \mathrm{~h}$ (b). Bar, $10 \mu \mathrm{m}$.

discriminated from P. vibrioides (Biebl et al., 2000), while spore-forming cells were somewhat thicker (Fig. 1).

Temperature and $\mathrm{pH}$ range and substrate utilization were assessed in $16 \mathrm{ml}$ screw-cap Hungate tubes (Bellco), using the test medium of Holdeman et al. (1977). Growth was monitored by measuring the optical density of the entire tube at $600 \mathrm{~nm}$. Strain $\mathrm{KS}^{\mathrm{T}}$ behaved as a mesophilic organism, with good growth between 20 and $50^{\circ} \mathrm{C}$, and an optimum at $37^{\circ} \mathrm{C}$. A maximum growth rate of $0.55 \mathrm{~h}^{-1}$ was measured. The $\mathrm{pH}$ range for growth was between $5 \cdot 0$ and $8 \cdot 5$, with an optimum at $6 \cdot 8$. Yeast extract was required at a minimum of $0.5 \mathrm{~g} \mathrm{l}^{-1}$.

Only a limited number of carbon and energy sources was utilized by strain $\mathrm{KS}^{\mathrm{T}}$, mainly sugars and sugar alcohols, including glycerol (see species description). 1,3-Propanediol and adipate, the depolymerization products of the polyester SP 3/6, did not support growth, nor were the products of other polymers decomposed by the strain (see below): 1,4-butanediol, caproate and terephthalate. The fermentation products were determined by GC (Biebl et al., 2000). It was shown that all utilized substrates were fermented to propionic and acetic acid, $\mathrm{CO}_{2}$ and $\mathrm{H}_{2}$. The fermentation balances, as determined in tightly sealed Hungate tubes, are shown in Table 1.
In addition to the polyester SP 3/6, strain $\mathrm{KS}^{\mathrm{T}}$ was able to hydrolyse other synthetic polymers, such as SP $4 / 6$, the condensate of 1,4-butanediol and adipic acid, and poly ( $\varepsilon$-caprolactone). The copolymer of 1,4-butanediol, terephthalic acid and adipic acid (BTA), which exhibits better material properties than the aliphatic polyesters, was weakly degraded, as long as the aromatic component did not exceed $20 \%$ of the acidic components. Natural polyesters, such as polyhydroxybutyrate (PHB) and poly(hydroyxybutyratehydroxyvalerate) (PHBS), were not attacked. The course of depolymerization of these compounds, shown as the increase in the clear zone diameter in agar, can be viewed as Supplementary Fig. A in IJSEM Online. Although the ability to depolymerize synthetic polyesters may be significant for their degradation in nature, it appears to be without significance for the metabolism of the organism, as the products are not further decomposed. The depolymerizing enzyme seems to be a non-specific enzyme, probably a lipase, which affects the ester bonds of the synthetic polymer.

Genomic-DNA extraction, PCR-mediated amplification of the 16S rRNA gene and sequencing of PCR products was carried out as described by Rainey et al. (1996). Purified PCR products were sequenced directly using the Taq

Table 1. Fermentation balances of strain $\mathrm{KS}^{\top}$ from various carbon substrates

\begin{tabular}{|c|c|c|c|c|c|c|}
\hline \multirow[t]{2}{*}{ Substrate } & \multicolumn{4}{|c|}{$\begin{array}{c}\text { Product recovery } \\
\text { (mol per } 100 \text { mol substrate) }\end{array}$} & \multirow[t]{2}{*}{$\begin{array}{c}\text { Carbon } \\
\text { recovery }(\%)\end{array}$} & \multirow[t]{2}{*}{$\begin{array}{c}\text { Electron } \\
\text { recovery }(\%)\end{array}$} \\
\hline & $\begin{array}{l}\text { Propionic } \\
\text { acid }\end{array}$ & $\begin{array}{l}\text { Acetic } \\
\text { acid }\end{array}$ & $\mathrm{CO}_{2}$ & $\mathrm{H}_{2}$ & & \\
\hline Glucose & 119 & 60 & 75 & 2 & 92 & 90 \\
\hline Fructose & 104 & 55 & 67 & 5 & 82 & 80 \\
\hline Mannitol & 119 & 55 & 55 & 21 & 87 & 83 \\
\hline Xylitol & 90 & 40 & 40 & 15 & 78 & 75 \\
\hline Erythritol & 98 & 29 & 35 & 16 & 96 & 91 \\
\hline Glycerol & 79 & 24 & 37 & 23 & 108 & 97 \\
\hline
\end{tabular}


DyeDeoxy Terminator Cycle Sequencing kit (Applied Biosystems), according to the manufacturer's instructions. An Applied Biosystems 373A DNA genetic analyser was used for electrophoresis of the sequence reaction products. Although nearly complete sequence determination was achieved by this method, part of the $5^{\prime}$ region of the gene, corresponding to helix 6 (De Rijk et al., 1992), could not be resolved. In accordance with the characterization of P. vibrioides (Biebl et al., 2000), the $16 \mathrm{~S}$ rRNA gene PCR product had to be cloned to resolve the sequence in this region. Insertions of about $119 \mathrm{nt}$ were found in several individual clones (data not shown). For alignment and subsequent analysis, sequences from clones carrying no insertion were used.

Using the ae2 editor (Maidak et al., 1999), the almost complete 16S rRNA gene sequence of one clone of strain $\mathrm{KS}^{\mathrm{T}}$ was aligned manually with those of all currently available nucleotide sequences of the Sporomusa-SelenomonasPectinatus group retrieved from GenBank and EMBL. The method of Jukes \& Cantor (1969) was used to calculate evolutionary distances. Phylogenetic dendrograms were reconstructed according to the method of De Soete (1983) and the neighbour-joining and maximum-likelihood methods contained in the PHYLIP package (Felsenstein, 1993). The highest binary similarity value was found to the sequence of $P$. vibrioides (97.9\%). Lower values, ranging between 92.2 and $89.8 \%$, were found for the type strains of Sporomusa species. Different treeing algorithms (De Soete, 1983; Felsenstein, 1993) placed the novel strain on a separate line of descent together with $P$. vibrioides (Fig. 2).

The DNA-DNA hybridization between $P$. vibrioides strain FKBS1 $^{\mathrm{T}}\left(=\mathrm{DSM} 13305^{\mathrm{T}}\right)$ and strain $\mathrm{KS}^{\mathrm{T}}$ was $46 \cdot 7 \%$. The $\mathrm{G}+\mathrm{C}$ content was $42.3 \mathrm{~mol} \%$ for strain $\mathrm{KS}^{\mathrm{T}}$ and $48 \cdot 7 \mathrm{~mol} \%$ for strain $\mathrm{FKBS}^{\mathrm{T}}$.

With the isolation of strain $\mathrm{KS}^{\mathrm{T}}$, a second representative of the genus Propionispora (Biebl et al., 2000) was found. This genus possesses properties that also occur in other related genera belonging to the Selenomonas-SporomusaPectinatus group (Strömpl et al., 1999), but in an unusual combination. It shares the typical cellular organization, i.e. vibrio-shaped cells with flagella inserted at the concave side, with Selenomonas and Sporomusa, and the ability to form spores with Sporomusa and Dendrosporobacter. The strain ferments propionic acid, in common with many other members of the group, including Selenomonas, but not Sporomusa, which is acetogenic (Möller et al., 1984).

Strain $\mathrm{KS}^{\mathrm{T}}$ matches the type strain (DSM $13304^{\mathrm{T}}$ ) of $P$. vibrioides in essential criteria. Cells are vibrio-shaped and form terminal, round spores. They produce propionic and acetic acid from a limited number of sugars and sugar alcohols. However, there are differences in the utilization of glucose and glycerol, which are not attacked by the $P$. vibriodes strain. Also, spore-forming $\mathrm{KS}^{\mathrm{T}}$ cells are distinctly thicker than those of $P$. vibrioides. The $16 \mathrm{~S}$ rRNA gene sequence similarity between KS and $P$. vibrioides of

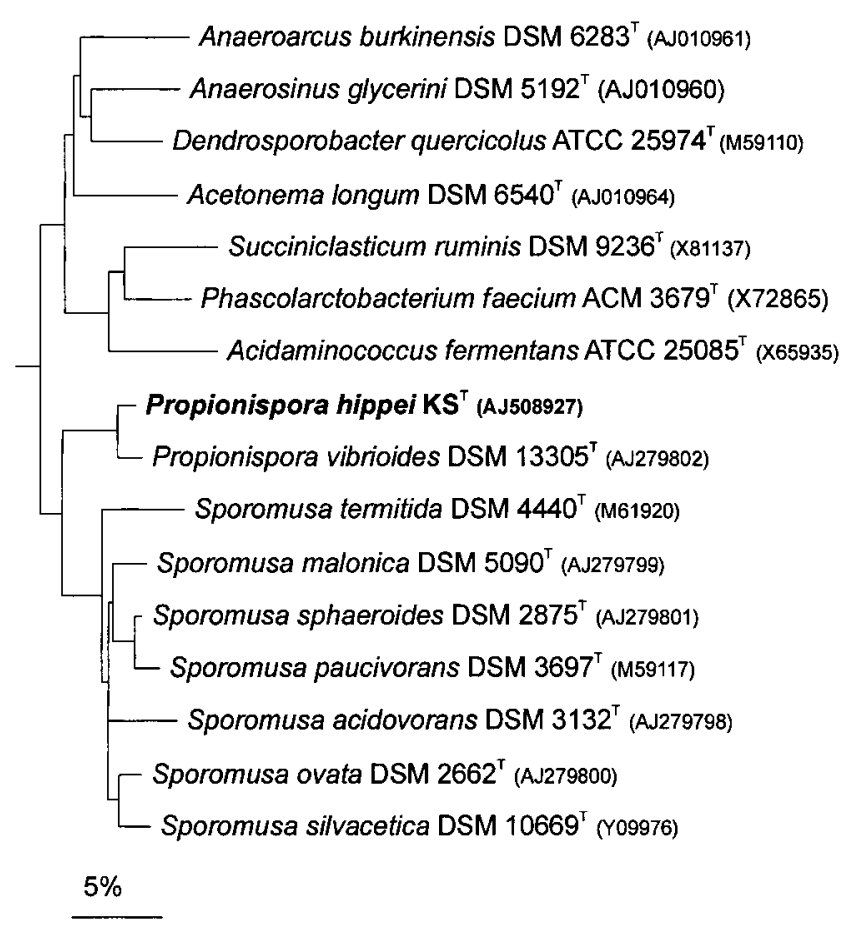

Fig. 2. $16 S$ rRNA gene sequence dendrogram showing the phylogenetic position of strain $\mathrm{KS}^{\top}$. Bar, 5 nt substitutions per $100 \mathrm{nt}$.

97.9\% corresponds to values found among Sporomusa species (mean, 97\%). The DNA-DNA hybridization was far below $70 \%$, indicating an evolutionary distance at the species level (Johnson, 1984). We therefore propose to classify strain $\mathrm{KS}^{\mathrm{T}}$ as a separate species within the genus Propionispora as Propionispora hippei sp. nov.

\section{Description of Propionispora hippei sp. nov.}

Propionispora hippei (hip'.pe.i. N.L. gen. n. hippei named after Dr Hans-H. Hippe, DSMZ, for his numerous contributions to the cultivation and taxonomy of anaerobes).

Cells appear as vibrios to slightly curved rods in phasecontrast microscopy. Spores are round and in terminal position; spore-forming cells are distinctly swollen. Growth and fermentation substrates are glucose, fructose, mannitol, xylitol, erythritol and glycerol. Propionic and acetic acids are the fermentation products. Lactose, lactate, pyruvate, 3-hydroxybutyrate, 2,3-butanediol, ethanol, methanol and $\mathrm{H}_{2} / \mathrm{CO}_{2}$ are not used. Yeast extract is required. The species differs from $P$. vibrioides in its ability to ferment glucose and glycerol. It depolymerizes the aliphatic polyesters of 1,3-propanediol or 1,4-butanediol and adipic acid, as well as poly( $\varepsilon$-caprolactone $)$, without degrading the monomers.

The type strain is strain $\mathrm{KS}^{\mathrm{T}}\left(=\mathrm{DSM} 15287^{\mathrm{T}}=\mathrm{ATCC}\right.$ BAA $-665^{\mathrm{T}}$ ), isolated from an enrichment culture for decomposition of the aliphatic copolyester of 1,3-propanediol and adipic acid. 


\section{Acknowledgements}

We thank I. Kramer and A. Samuels for skilful technical assistance. D. M. A.-Z. gratefully acknowledges the support of a scholarship from DAAD (Deutscher Akademischer Austauschdienst).

\section{References}

Abou-Zeid, D. M. (2001). Anaerobic biodegradation of natural and synthetic polyesters. Dissertation. Technische Universität CaroloWilhelmina zu Braunschweig, Germany. http://opus.tu-bs.de/opus/ volltexte/2001/246

Abou-Zeid, D. M., Müller, R.-J. \& Deckwer, W.-D. (2001). Degradation of natural and synthetic polyesters under anaerobic conditions. J Biotechnol 86, 113-126.

Biebl, H., Schwab-Hanisch, H., Spröer, C. \& Lünsdorf, H. (2000). Propionispora vibrioides, nov. gen., nov. sp., a new gram-negative, spore-forming anaerobe that ferments sugar alcohols. Arch Microbiol 174, 239-247.

De Rijk, P., Neefs, J.-M., Van de Peer, Y. \& De Wachter, R. (1992). Compilation of small ribosomal subunit RNA sequences. Nucleic Acids Res 20, 2075-2089.

De Soete, G. (1983). A least squares algorithm for fitting additive trees to proximity data. Psychometrica 48, 621-626.

Felsenstein, J. (1993). PHYLIP (phylogenetic inference package), version 3.5c. Department of Genetics, University of Washington, Seattle, USA

Holdeman, L. V., Cato, E. P. \& Moore, W. E. C. (1977). Anaerobe Laboratory Manual, 4th edn. Blacksburg, VA: Virginia Polytechnic Institute and State University.
Johnson, J. L. (1984). Nucleic acids in bacteria classification. In Bergey's Manual of Systematic Bacteriology, vol. 1, pp. 8-11. Edited by N. R. Krieg \& J. G. Holt. Baltimore: Williams \& Wilkins.

Jukes, T. H. \& Cantor, C. R. (1969). Evolution of protein molecules. In Mammalian Protein Metabolism, pp. 21-132. Edited by H. N. Munro. New York: Academic Press.

Maidak, B. L., Cole, J. R., Parker, C. T. \& 11 other authors (1999). A new version of the RDP (Ribosomal Database Project). Nucleic Acids Res 27, 171-173.

Möller, B., Oßmer, R., Howard, B. H., Gottschalk, G. \& Hippe, H. (1984). Sporomusa, a genus of gram-negative anaerobic bacteria including Sporomusa sphaeroides sp. nov., and Sporomusa ovata, sp. nov. Arch Microbiol 139, 388-396.

Rainey, F. A., Ward-Rainey, N., Kroppenstedt, R. M. \& Stackebrandt, E. (1996). The genus Nocardiopsis represents a phylogenetically coherent taxon and a distinct actinomycete lineage: proposal of Nocardiopsaceae fam. nov. Int J Syst Bacteriol 46, 1088-1092.

Strömpl, C., Tindall, B. J., Jarvis, G. N., Lünsdorf, H., Moore, E. R. B. \& Hippe, H. (1999). A re-evaluation of the taxonomy of the genus Anaerovibrio, with the reclassification of Anaerovibrio glycerini as Anaerosinus glycerini gen. nov., comb. nov., and Anaerovibrio burkinabensis as Anaeroarcus burkinensis [corrig.], gen. nov., comb. nov. Int J Syst Bacteriol 49, 1861-1872.

Witt, U., Müller, R.-J. \& Deckwer, W.-D. (1994). Biodegradation of polyester copolymers containing aromatic compounds. J Macromol Sci Pure Appl Chem A 32, 851-856. 